\title{
Numerical-computational analysis of reinforced concrete structures considering the damage, fracture and failure criterion
}

\section{Análise numérico-computacional de estruturas de concreto armado considerando o dano, a fratura e critério de falha}

L. A. F. DE SOUZA a lafarani@yahoo.com.br

R. D. MACHADO b

\begin{abstract}
The experimental results of testing structures or structural parts are limited and, sometimes, difficult to interpret. Thus, the development of mathematical-numerical models is needed to complement the experimental analysis and allow the generalization of results for different structures and types of loading. This article makes two computational studies of reinforced concrete structures problems found in the literature, using the Finite Element Method. In these analyses, the concrete is simulated with the damage classical model proposed by Mazars and the steel by a bilinear elastoplastic constitutive model. Numerical results show the validity of the application of constitutive models which consider the coupling of theories with the technique of finite element discretization in the simulation of linear and two-dimensional reinforced concrete structures.
\end{abstract}

Keywords: damage mechanics, line interface element, fracture, softening, failure criterion.

\section{Resumo}

Os resultados obtidos a partir de ensaios de estruturas ou de peças estruturais em laboratório são limitados e, às vezes, de difícil interpretação. Dessa forma, o desenvolvimento de modelos numérico-matemáticos se faz necessário para complementar a análise experimental e possibilitar a generalização dos resultados para diferentes estruturas e tipos de carregamento. Este artigo faz dois estudos computacionais de problemas de estruturas de concreto armado encontrados na literatura, utilizando o Método dos Elementos Finitos. Nas análises, o concreto é simulado com o modelo clássico de dano proposto por Mazars e o aço por um modelo constitutivo elastoplástico bilinear. Os resultados numéricos mostram a validade da aplicação de modelos constitutivos que consideram o acoplamento de teorias com a técnica de discretização por elementos finitos na simulação do comportamento de estruturas lineares e bi-dimensionais em concreto armado.

Palavras-chave: mecânica do dano, elemento de interface de linha, fratura, amolecimento, critério de falha.

a Professor Doutor, Engenharia Ambiental, UFFS - Universidade Federal da Fronteira Sul - UFFS, Campus Cerro Largo, Rua Major Antônio Cardoso, 590, Cerro Largo - Rio Grande do Sul - Brasil - e-mail: lafarani@yahoo.com.br - tel.: (55) 3359 - 3950;

b Professor Doutor, Programa de Pós-Graduação em Engenharia Mecânica, PUCPR - Departamento de Engenharia Mecânica - Pontifícia Universidade Católica - PUC PR - Rua Imaculada Conceição, 1.155 - Prado Velho - Curitiba - Brasil. 


\section{Introduction}

Concrete has been the most used structural material in the world in the past sixty years. It is employed in all types of construction for its several advantages: easily malleable, adapting itself to any kind of form; fire resistant, resistant to the atmospheric influences and to mechanical wear; and it is an economic alternative for it is built with low cost raw material.

One of the difficulties in the concrete structures computational modeling is the definition of the constitutive relationships that consider the non-linear behavior of the material and, the potential cracking and the different responses to tensile and compression stresses. It is very difficult to separate the deformation and rupture phenomena in the concrete for the microcracks and the hollows that exist even before any stress is applied, interfere directly in the initial response of the moving material (Lemaitre and Chaboche [8]).

Analyses of reinforced concrete structures based on elastic material models (linear or non-linear) are widely used in design offices nowadays and the results are employed in the sizing and evaluation of their global behavior. When these structures are subjected to loadings that cause the beginning of cracks in the concrete in tensile stress, the elastic analyses are not able to properly simulate this behavior (Leonel et al. [9]).

The Plasticity, Damage Mechanics and Fracture Mechanics theories are widely used in structure analysis of reinforced concrete, each one of them being appropriate to simulate such phenomenon. As there is no complete constitutive model for the concrete yet, the trend is to employ a set of these theories for representing the phenomena related to the material behavior.

A natural evolution are the models that couple more than one theory, creating formulations that are almost always complex. However, aiming to decrease the complexity of the formulations, but still taking into account the coupling of the effects in the formulation, and due to theories, a great highlight has been given to the so called simplified constitutive models (Álvares et al. [1]).

In general, the concrete destruction can be divided into two types: the first one happens by tensile stress and it is characterized by crack formation and loss of tensile stress resistance in the normal direction to the cracks formed; the second one is due to compression, and it is characterized by the formation of multiple cracks parallel to the compression force. The cracks from the later have a smaller size which make the concrete lose a great part of its strength.

A strength criterion aims to establish laws through which it is possible to predict the rupture condition under any type of stress or strain combination through the material behavior in the simple tensile and compression tests (Nicolas et al. [12]). Many of the existing strength criteria present restrictions in relation to the application to heterogeneous and anisotropic materials with directional strength and elasticity properties such as concrete. Therefore, the investigation of a strength criterion that allows a proper evaluation of the rupture of this material to an axial or biaxial stress state becomes important and necessary.

This article presents two modeling proposals for reinforced concrete structures through two numerical computational studies using the Finite Element Method aiming to analyze the aspects involved in computational modeling including items related to constitutive models of the materials. The non-linear analyses are carried out considering the arc-length method with the modified Newton-Raphson iterative process. This technique is characterized by presenting a concomitant load and displacement control.

The first study consists of the one-dimensional structural analysis of a beam proposed by Jarek et al. [7]. The modeling of this structural element is made with the Scilab program, version 5.3.3. The concrete behavior is simulated by the damage constitutive model proposed by Mazars [10] and, the steel by a bilinear elastoplastic constitutive model. Tsai and Wu's [18] failure criterion is also incorporated to the model.

From the two-dimensional problem of an adapted reinforced pull rod from Mazars and Pijaudier-Cabot [11], the second study analyses the structural response considering the damage constitutive model coupling proposed by Mazars [10] and a rupture model in Mode I based on the work of Schellekens [16]. This model was implemented in Fortran code - Compaq Visual Fortran Edition 6.5. The crack is simulated though a line interface element and the softening phenomenon can be considered - linear, bilinear or exponential - in the constitutive model.

\section{Constitutive model for the concrete}

The damage model proposed by Mazars [10] is based on a couple of experimental evidences observed in uniaxial tests of concrete specimens, having as basic hypotheses (Proença [14]):

- locally, the damage is due to extensions (elongations) evidenced by positive signs; at least by one of them, the main strain components $\left(\varepsilon_{i}>0\right)$;

- the damage is represented by a scalar variable $D \in[0.1]$ which evolution happens when a reference value for the 'equivalent elongation' is overcome;

- it is considered, however, that the damage is isotropic although the experimental analyses show that the damage leads, in general, to a an anisotropy of the concrete (which can be initially considered as isotropic), and

- the damaged concrete behaves as an elastic medium. Thus, the permanent strains that were experimentally evidenced in an unloading situation are disregarded.

In this model, it is supposed that the damage begins when the equivalent strain reaches a reference strain value $\varepsilon_{d 0}$, determined in uniaxial tensile tests in relation to the maximum stress. The constitutive relation is given by (Tiago et al. [17]):

$$
\sigma=(I-D I) C^{o}
$$

Where $\boldsymbol{I}$ is the identity tensor and $\boldsymbol{C}^{0}$ is the elastic tensor of the undamaged material. The extension state is locally characterized by an equivalent strain that is expressed by (Pituba and Proença [13]):

$$
\tilde{\epsilon}=\sqrt{\left.\left\langle\epsilon_{1}\right\rangle_{+}^{2}+\left\langle\epsilon_{2}\right\rangle_{+}^{2}+<\epsilon_{3}\right\rangle_{+}^{2}}
$$


Where $\varepsilon_{i}, i=1, \ldots, 3$, are main strain components and $\left\langle\varepsilon_{i}\right\rangle_{+}, i=$ $1, \ldots, 3$, are the positive parts defined by:

$$
\left\langle\epsilon_{\mathrm{i}}\right\rangle_{+}=\frac{1}{2}\left(\epsilon_{\mathrm{i}}+\left|\epsilon_{\mathrm{i}}\right|\right)
$$

The concrete, with regards to the rupture modes, presents a distinct behavior in relation to the tensile and compression stresses. The concrete rupture by tensile strengths happens due to crack formation and the consequent loss of normal strength in the direction of the crack. As for the damage during compression, the concrete presents a behavior that can be considered plastic, which is the crushing caused by the internal cohesion being overcome due to the shear stress characterized by a large quantity of microcracks (Leonel et al. [9]).

Considering a continuously increasing or radial loading of the stress-strain curves obtained in tensile and compression uniaxial tests, the damage variables $D_{T}$ and $D_{C}$ can be explicitly determined the following way, respectively:

$$
\mathrm{D}_{\mathrm{T}}(\widetilde{\varepsilon})=1-\frac{\varepsilon_{\mathrm{d} 0}\left(1-\mathrm{A}_{\mathrm{T}}\right)}{\widetilde{\varepsilon}}-\frac{\mathrm{A}_{\mathrm{T}}}{\mathrm{e}\left(\mathrm{B}_{\mathrm{T}} \tilde{\varepsilon}-\varepsilon_{\mathrm{d} 0}\right)}
$$

$$
\mathrm{D}_{\mathrm{c}}(\widetilde{\varepsilon})=1-\frac{\varepsilon_{\mathrm{d} 0}\left(1-\mathrm{A}_{\mathrm{c}}\right)}{\widetilde{\varepsilon}}-\frac{\mathrm{A}_{\mathrm{c}}}{\mathrm{e}\left(\mathrm{B}_{\mathrm{T}} \tilde{\varepsilon}-\varepsilon_{\mathrm{d} 0}\right)}
$$

Where $A_{T}$ and $B_{T}$ are characteristic parameters of the material in uniaxial tensile stress, $A_{C}$ and $B_{C}$ are parameters of the material in uniaxial compression stress and $\varepsilon_{d 0}$ is the limiting elastic strain. The subindexes $T$ and $C$ mean tensile and compression, respectively. For complex stress states, the variable for damage can be determined by a linear combination of $D_{T}$ and $D_{C}$ by means of the following condition (Pituba and Proença [13]):

$$
\mathrm{D}=\alpha_{\mathrm{T}} \mathrm{D}_{\mathrm{T}}(\tilde{\varepsilon})+\alpha_{\mathrm{C}} \mathrm{D}_{\mathrm{c}}(\tilde{\varepsilon}), \alpha_{\mathrm{T}}+\alpha_{\mathrm{C}}=1
$$

Where the coefficients $\alpha_{T}$ and $\alpha_{C}$ take on values in the closed interval $[0,1]$, and represent the contribution of the tensile and compression stresses to the local extension state, respectively. Mazars [10] proposed the following variation limits for the parameters $A_{T}, B_{T}$, $A_{C}$ and $B_{C}$, obtained from the calibration with experimental results: $0,7 \leq A_{T} \leq 1 \quad 10^{4} \leq B_{T} \leq 10^{5} \quad 1 \leq A_{C} \leq 1,5 \quad 10^{3} \leq B_{C} \leq 210^{3}$ $10^{-5} \leq \leq 210^{-4}$

\section{Constitutive model for steel}

In this work, a uniaxial model is used to describe the behavior of armatures, once, in reinforced concrete structures, the steel bars essentially resist axial strains. In the implemented computational model, the steel is represented as an elastoplastic material and it has the same behavior in tensile and compression stresses. The schematic is given by a bilinear stress-strain diagram. Thus, the stress in steel is determined by (Tiago et al. [17]):

$$
\sigma= \begin{cases}E_{\mathrm{a}} \varepsilon, & -\varepsilon_{\mathrm{sy}} \leq \varepsilon \leq \varepsilon_{\mathrm{sy}} \\ \mathrm{E}_{\mathrm{at}} \varepsilon, & \text { otherwise }\end{cases}
$$

Where $E_{a}$ is the initial longitudinal modulus of elasticity for steel, $\varepsilon_{s y}$ is the yielding extension and $E_{a t}=k_{a} E_{a}$ is the longitudinal modulus of elasticity after the steel yielding.

\section{Line interface element}

The geometrical discontinuities can be successfully modeled using interface finite elements. These elements aim to transmit the stresses between either bodies or parts of the same body among which it is found.

Line interface elements were used in this paper in order to simulate pre-established cracks in the part, assuming cracking mode I. Mode I effect is represented by the transmission of stresses that are normal to the crack faces.

The line interface element is based on the work of Schellekens [16]. This one-dimensional element is isoparametric, with four nodal points (two degrees of freedom per node $-u, v$ ), linear shape functions and zero thickness.

The nodal displacement vector $\boldsymbol{u}$ is given by:

$$
\mathrm{u}=\left[\begin{array}{llllllll}
\mathrm{u}_{1} & \mathrm{v}_{1} & \mathrm{u}_{2} & \mathrm{v}_{2} & \mathrm{u}_{3} & \mathrm{v}_{3} & \mathrm{u}_{4} & \mathrm{v}_{4}
\end{array}\right]^{\mathrm{T}}
$$

Where $u_{i}$ and $v_{i}, i=1, \ldots, 4$, are the nodal displacements in the direction $\xi$ and $\eta$, respectively. Operator $\boldsymbol{B}$, which relates the nodal displacements to the displacement field regarding the element, is:

$$
\mathrm{B}=\left[\begin{array}{cccccccc}
\mathrm{h}_{1} & 0 & \mathrm{~h}_{2} & 0 & \mathrm{~h}_{3} & 0 & \mathrm{~h}_{4} & 0 \\
0 & \mathrm{~h}_{1} & 0 & \mathrm{~h}_{2} & 0 & \mathrm{~h}_{3} & 0 & \mathrm{~h}_{4}
\end{array}\right]
$$

Where $h_{i}, i=1, \ldots, 4$, are the shape functions given by:

$$
\mathrm{h}_{1}=\mathrm{h}_{4}=\frac{1}{2}(1-\xi)
$$

$$
\mathrm{h}_{2}=\mathrm{h}_{3}=\frac{1}{2}(1+\xi)
$$

Usually, the stresses are evaluated as a function of the strains; however, in the case of the stresses in the interface, those are determined 
as a function of the relative displacements. The relative displacements $(\Delta \boldsymbol{w})$ of the element are calculated through the following relation:

$$
\Delta \mathrm{w}=\mathrm{Bu}
$$

$D$ being the matrix of the material properties and, considering that the line interface element has no dimension in the direction $\eta$ and that the thickness $e$ is constant along the length of the material, the stiffness matrix $K$ is obtained by:

$$
\mathrm{K}=\mathrm{e} \int_{\xi=-1}^{\substack{\xi=1 \\ \xi=1}} \mathrm{~B}^{\mathrm{T}} \mathrm{DB} \frac{\partial \mathrm{L}}{\partial \xi} \mathrm{d} \xi
$$

Where $L$ is the length of the element. The constitutive matrix $\boldsymbol{D}$ is given by:

$$
\mathrm{D}=\left[\begin{array}{cc}
\mathrm{K}_{\mathrm{S}} & 0 \\
0 & \mathrm{~K}_{0}
\end{array}\right]
$$

Where $K_{S}$ and $K_{0}$ denote the horizontal stiffness components (tangential stiffness) and vertical stiffness (tensile stiffness), respectively. When calculating the matrix stiffness components, $\boldsymbol{D}$, the softening phenomenon - linear, bilinear or exponential - can be considered in the constitutive model.

The linear softening model disregards the tangential cohesive effects and simplifies the tensile stiffness curve, considering that the material loses its strength from the beginning. Matrix $D$ can be written the following way:

$$
\mathrm{D}=\left[\begin{array}{cc}
0 & 0 \\
0 & \mathrm{~K}_{0}^{\prime}
\end{array}\right] \Rightarrow\left\{\begin{array}{c}
\mathrm{w} \leq \mathrm{w}_{\mathrm{c}} \rightarrow \mathrm{K}_{0}{ }^{\prime}=\mathrm{K}_{0}\left(\frac{\mathrm{w}_{\mathrm{c}}-\mathrm{w}}{\mathrm{w}_{\mathrm{c}}}\right) \\
\mathrm{w}>\mathrm{w}_{\mathrm{c}} \rightarrow \mathrm{K}_{0}{ }^{\prime}=0
\end{array}\right.
$$

Where $w_{c}$ is the critical relative displacement from which there is no transmission of stresses between the crack faces, $K_{0}$ is the initial tensile stiffness and, $w$ is the opening between the nodes of the element that has a normal interface in relation to the crack faces. The opening of the critical crack $\left(w_{c}\right)$, in the case of linear softening, is obtained from the fracture energy $\left(G_{f}\right)$ and it is given by:

$$
\mathrm{w}_{\mathrm{c}}=\frac{2 \mathrm{G}_{\mathrm{F}}}{\sigma_{\mathrm{U}}}
$$

Where $\sigma_{u}$ is the ultimate tensile stress of the material. This model is in agreement with the Fracture Mechanics principles, for the area limited by the stress curve transmitted through the crack versus the opening of the crack $(\sigma \times w)$ is equal to the fracture energy of the material $\left(G_{f}\right)$.
The constitutive model of the exponential softening is characterized by the curve in which the tensile stiffness decreases exponentially in relation to the relative displacement. The contribution of the tangential stiffness component is disregarded in this model. Matrix $D$ can be written by:

$$
\mathrm{D}=\left[\begin{array}{cc}
0 & 0 \\
0 & \mathrm{~K}_{0}^{\prime}
\end{array}\right] \Rightarrow\left\{\begin{array}{c}
\mathrm{w} \leq \mathrm{w}_{\mathrm{c}} \rightarrow \mathrm{K}_{0}{ }^{\prime}=\mathrm{K}_{0} \mathrm{e}^{-\theta \mathrm{w}} \\
\mathrm{w}>\mathrm{w}_{\mathrm{c}} \rightarrow \mathrm{K}_{0}^{\prime}=0
\end{array}\right.
$$

Where $\theta$ is the exponential softening coefficient. The fracture energy $\left(G_{f}\right)$ for the exponential softening can be obtained by integrating the constitutive law and varying the opening of the crack from 0 to $\propto$, where we have:

$$
\mathrm{G}_{\mathrm{f}}=\frac{\sigma_{\mathrm{u}}}{\Theta}
$$

The bilinear constitutive model is characterized by a curve with two different slopes, considering that the material loses its strength from the beginning of the stress. Matrix $D$ can be written the following way:

$$
\mathrm{D}=\left[\begin{array}{cc}
0 & 0 \\
0 & \mathrm{~K}_{0}^{\prime}
\end{array}\right] \Rightarrow\left\{\begin{array}{c}
\mathrm{w} \leq \mathrm{w}_{1} \rightarrow \mathrm{K}_{0}{ }^{\prime}=\mathrm{K}_{0}+\frac{\left(\mathrm{K}_{1}-\mathrm{K}_{0}\right) \mathrm{w}}{\mathrm{w}_{1}} \\
\mathrm{w}_{1}<\mathrm{w}=\mathrm{w}_{\mathrm{c}} \rightarrow \mathrm{K}_{0}{ }^{\prime}=\frac{\mathrm{K}_{1}\left(\mathrm{w}-\mathrm{w}_{\mathrm{c}}\right)}{\mathrm{w}_{1}-\mathrm{w}_{\mathrm{c}}} \\
\mathrm{w}>\mathrm{w}_{\mathrm{c}} \rightarrow \mathrm{K}_{0}^{\prime}=0
\end{array}\right.
$$

Where $w_{1}$ is the opening of the crack and $K_{1}$ is the tensile stiffness from which the relation stiffness-opening follows the other constitutive law. In case of bilinear softening, the critical opening of the crack $w_{c}$ is obtained by:

$$
\mathrm{w}_{\mathrm{c}}=\frac{2 \mathrm{G}_{\mathrm{F}}}{\sigma_{\mathrm{U}}}-\mathrm{w}_{1}-\frac{2 \sigma_{\mathrm{U}}}{\sigma_{1}}
$$

Where $\sigma_{1}$ is the tensile stress of the material for an opening equal to $w_{1}$.

\section{Tsai and Wu's strength criterion}

The procedure proposed by Tsai and $\mathrm{Wu}$ [18] was to increase the number of terms in Hill's [6] failure criterion equation for a better approximation of the experimental data obtained for several materials. The failure of a certain material is interpreted as the occurrence of any discontinuity in the material response to the mechanical stimuli (Nicolas et al. [12]). Some of the discontinuities of interest are: the beginning of the non-linearity in the relation stress versus strain, the occurrence of irreversible strains and material rupture. The conditions for the occurrence of these phenomena 
are referred to as failure or rupture criterion. The fragile rupture condition must be considered as a special case in which the failure criterion due to yielding corresponds to the failure criterion due to rupture (Gagliardo et al. [3]).

Considering totally anisotropic materials, it must be admitted that the failure modes are conditioned both by the normal and tangential stresses, considering that the fractures may occur due to different sets of stresses that act on the element. In a general way, this theory may be presented by:

$\sum_{\mathrm{i}=1}^{6} \mathrm{~F}_{\mathrm{i}} \sigma_{\mathrm{i}}+\sum_{\mathrm{i}=1}^{6} \sum_{\mathrm{j}=1}^{6} \mathrm{~F}_{\mathrm{ij}} \sigma_{\mathrm{i}} \sigma_{\mathrm{j}}+\sum_{\mathrm{i}=1}^{6} \sum_{\mathrm{j}=1}^{6} \sum_{\mathrm{k}=1}^{6} \mathrm{~F}_{\mathrm{ijk}} \sigma_{\mathrm{i}} \sigma_{\mathrm{j}} \sigma_{\mathrm{k}}+\ldots=1$

The coefficients $F_{i}, F_{i j}$ and $F_{i j k}$ are tensor rearranged structures of the $1^{\text {st }}, 2^{\text {nd }}$ and $3^{\text {rd }}$ order, respectively. An advantage of this method is that it is possible to use as many terms as are necessary for the approximation of experimental points of a material. However, once each constant is associated with a unique type of mechanical test for its determination, Equation 21 is normally restricted to $2^{\text {nd }}$ order terms. If this is not done, the quantity and complexity of the necessary tests for determining the constants would make the method impracticable. Thus, Equation 21 is reduced to:

$$
\sum_{\mathrm{i}=1}^{6} \mathrm{~F}_{\mathrm{i}} \sigma_{\mathrm{i}}+\sum_{\mathrm{i}=1}^{6} \sum_{\mathrm{j}=1}^{6} \mathrm{~F}_{\mathrm{ij}} \sigma_{\mathrm{i}} \sigma_{\mathrm{j}}=1
$$

Considering a plane state of stresses applied to orthotropic materials, and developing Equation (22), we have:

$$
\mathrm{F}_{1} \sigma_{1}+\mathrm{F}_{2} \sigma_{2}+\mathrm{F}_{11} \sigma_{1}{ }^{2}+\mathrm{F}_{22} \sigma_{2}^{2}+2 \mathrm{~F}_{12} \sigma_{1} \sigma_{2}+\mathrm{F}_{44} \sigma_{4}^{2}=1
$$

Where $\sigma_{i}, i=1, \ldots, 3$, are the main stresses and $\sigma_{4}$ is the shear stress. Equation (23) indicates that the state of stresses is at a critical point (on the verge of the failure). However, if the state of stresses given by the left side of Equation (23) presents a numerical result lower than one, we have a safety situation. Different from other strength criteria, this one takes into consideration the effect of the hydrostatic components of the stresses.

\section{Arc-length method with the modified Newton-Raphson iterative process}

When applying the Newton-Raphson method for limit-point problems with a load control, the stiffness matrix tends to singularize around this point in its ascending trajectory. An alternative to detect and surpass the limit point is to use solution methods associated with the Newton-Raphson method, for instance, the arc-length method.

The arc-length method is characterized for presenting a concomitant control of the load and displacement. There are two variables: the increment of the load factor $\Delta \phi$ and the displacement increment vector $\Delta \boldsymbol{u}$. In each step of the solution, the iteration trajectories are perpendicular to the arcs, which in turn, can be approximated by tangents to the equilibrium trajectory at the initial points of these steps (Ramm [15]). Considering the arc-length method with the modified Newton-Raphson iterative process, the equilibrium equations for the i-th iteration can be written as:

$$
\mathrm{K}_{\mathrm{T}}^{\mathrm{a}} \Delta \mathrm{u}^{\mathrm{i}}=\Delta \varphi^{\mathrm{i}} \mathrm{R}_{0}+\Delta \mathrm{Q}^{\mathrm{i}-1}
$$

Where $\Delta \varphi^{\mathrm{i}}$ is the increment of the load factor of iteration $\mathrm{i}, \Delta \mathrm{u}^{\mathrm{i}}$ is the displacement increment vector, is the reference loads vector, $\mathrm{K}_{\mathrm{T}}{ }^{\mathrm{a}}$ is the updated tangential stiffness matrix only at the beginning of each loading step, and $\Delta Q^{i-1}$ is the non-balanced loads vector given by:

$$
\Delta \mathrm{Q}^{\mathrm{i}-1}=\mathrm{R}_{\text {ext }}^{\mathrm{i}-1}-\mathrm{F}_{\text {int }}^{\mathrm{i}}
$$

$\mathrm{R}_{\text {ext }}^{\mathrm{i}-1}$ being the external forces vector and is the internal nodal forces vector. Vector must be written as a function of the load factor, updated at the end of the previous iteration and the constant reference loads vector, through the following relation:

$$
\mathrm{R}_{\text {ext }}{ }^{\mathrm{i}-1}=\varphi^{\mathrm{i}-1} \mathrm{R}_{0}
$$

For a system of the $n+1$ order, $n$ being the number of degrees of freedom for the structure, we have:

$$
\left[\begin{array}{cc}
\mathrm{K}_{\mathrm{T}}{ }^{\mathrm{a}} & -\mathrm{R}_{0} \\
\Delta \mathrm{u}^{1} & \Delta \varphi^{1}
\end{array}\right]\left\{\begin{array}{c}
\Delta \mathrm{u}^{\mathrm{i}} \\
\Delta \varphi^{\mathrm{i}}
\end{array}\right\}=\left\{\begin{array}{c}
\Delta \mathrm{Q}^{\mathrm{i}-1} \\
0
\end{array}\right\}
$$

Where $\Delta \mathrm{u}^{1}$ is the first displacement increment vector of the solution step and $\Delta \varphi^{1}$ the first increment of the load factor in the given step. It can be noticed that the resolution of the system given in (27) creates a system of equations with non-trivial solution even if the matrix is singular, which is a great advantage for the solution of problems with limit point.

\subsection{Convergence criteria}

Aiming to limit the iterative processes, two convergence criteria are established: one for the displacements and another for the forces. The convergence criteria for the displacements must obey the following inequality:

$$
\frac{\left\|\Delta u^{i}\right\|}{\left\|u^{i}\right\|} \leq u_{\text {tol }}
$$


Where the numerator is the standard Euclidean norm of the displacement increment vector $\Delta \boldsymbol{u}^{i}$ correspondent to the $i$ iteration and the denominator is the Euclidian norm of the total displacement vector $\boldsymbol{u}^{i}=\boldsymbol{u}^{\boldsymbol{i}-1}+\Delta \boldsymbol{u}^{i}$ of the i-th iteration.

The convergence criteria of the forces must obey the relation:

$$
\frac{\left\|\Delta Q^{i}\right\|}{\left\|\varphi^{i} R_{0}\right\|} \leq Q_{\text {tol }}
$$

Where the numerator is the Euclidian norm of the non-balanced load increment correspondent to the $i$ iteration and the denominator is the Euclidian norm of the force increment for the solution step.

\section{Results and discussions}

\subsection{Simulation 1}

In this example, adapted from Jarek et al. [7], a one-dimensional non-linear analysis is carried out using the finite elements of a reinforced concrete beam, considering the damage model from Mazars [10] to simulate the concrete and the bilinear elastoplastic model for the steel. The criterion of Tsai and Wu [18] was adopted as the failure criterion for the concrete. The beam supported by two points is $6 \mathrm{~m}$ in length, rectangular cross-section of $(20 \times 40)$ $\mathrm{cm}^{2}$, subject to a condensed force applied in the middle of the gap. The lower longitudinal armatures $\left(A_{\text {st }}\right)$ and the upper longitudinal armatures $\left(A_{s c}\right)$ of the beam are constituted by $3 \phi 12.5 \mathrm{~mm}$, with a $0.02 \mathrm{~m}$ coating. The material parameters and strength coefficients for the Tsai and Wu's [18] criterion are presented in Table 1. In the finite element discretization, 100 beam elements with 2 nodes and 2 degrees of freedom/node were employed using the geometry and loading symmetry, analyzing thus, only half of the beam (Figure 1). The modified Newton-Raphson method combined with the arc-length technique was used in the solution of the non-linear equations. The load increment used was taken as equal to $0.5 \mathrm{kN}$. The maximum admitted errors at the end of each increment were $u_{t o l}=10^{-3}$ and $Q_{t o l}=10^{-2}$. In the analysis, the equivalent strain $\tilde{\varepsilon}$ is evaluated the following way (Tiago et al. [17]):

$$
\widetilde{\varepsilon}=\left\{\begin{array}{cc}
\varepsilon_{x} & , \varepsilon_{x} \geq 0 \\
-v \sqrt{2} \varepsilon_{x} & , \varepsilon_{x}<0
\end{array}\right.
$$

Where $v$ is the Poisson coefficient for the concrete.

The equivalent bending stiffness for the beam $\left(E l_{\text {eq }}\right)$ is determined considering two parcels. The first one refers to the equivalent bending stiffness for the concrete $\left(E l_{\text {eqc }}\right)$ and it is obtained by dividing the cross-section of the beam in $n$ layers. The moment of inertia $I$ for the i-th layer is calculated through the parallel axis theorem by:

$$
I_{i}=\frac{b\left(y_{i}-y_{i-1}\right)^{3}}{12}+b\left(y_{i}-y_{i-1}\right)\left(y_{i-1}+\frac{y_{i}-y_{i-1}}{2}\right)^{2}, i=1, \ldots, n
$$

Where $n$ is the total number of layers, $b$ is the width of the rectangular cross-section and $y_{i}$ is the coordinate for the i-th layer from the section centroid. The portion $E I_{\text {eqc }}$ is obtained by:

$$
\mathrm{EI}_{\mathrm{eqc}}=\Sigma_{\mathrm{i}=1}^{\mathrm{n}} \mathrm{E}_{\mathrm{ci}} \mathrm{I}_{\mathrm{i}}
$$

\begin{tabular}{|c|c|c|c|c|}
\hline \multirow[b]{2}{*}{ Concrete } & \multirow[b]{2}{*}{ Steel } & \multicolumn{3}{|c|}{ Tsai and Wu (18) } \\
\hline & & Coefficient & Equation & $\begin{array}{c}\text { Adopted values } \\
\text { (MPa) (Gagliardo } \\
\text { ef al. (3)) }\end{array}$ \\
\hline $\mathrm{E}_{\mathrm{c0}}=30.2 \mathrm{GPa}$ & $E_{\alpha}=210 \mathrm{GPa}$ & $\mathrm{F}_{1}$ & $\frac{1}{f_{t 1}}-\frac{1}{f_{c l}}$ & 0.224 \\
\hline$v=0.2$ & $v=0.3$ & $\mathrm{~F}_{2}$ & $\frac{1}{f_{t 2}}-\frac{1}{f_{c 2}}$ & 0 \\
\hline$A_{T}=0.995$ & $\mathrm{k}_{\mathrm{a}}=0.85$ & $\mathrm{~F}_{11}$ & $\frac{1}{f_{t 1} f_{c l}}$ & -0.0288 \\
\hline$B_{T}=10^{5}$ & & $\mathrm{~F}_{22}$ & $\frac{1}{f_{12} f_{c 2}}$ & 0 \\
\hline $\mathrm{A}_{c}=1.1$ & & $\mathrm{~F}_{44}$ & $\frac{1}{f_{v 4}^{2}}$ & 0.0305 \\
\hline $\mathrm{B}_{\mathrm{c}}=810^{3}$ & & $F_{12}$ & $\pm \sqrt{F_{11} F_{22}}$ & \pm 0.00385 \\
\hline
\end{tabular}

Table 1 - Parameters of the model 
Figure 1 - Structural model of the beam supported by two points
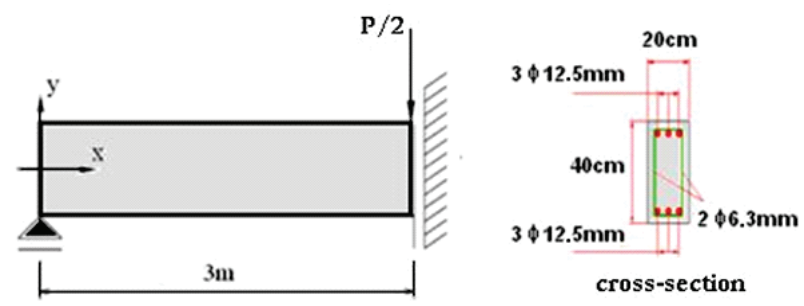

Where $E_{c i}=E_{c 0 i}\left(1-D_{j i}\right)$, with $j=C, T$, is the damaged concrete longitudinal elasticity module of the i-th layer. In this example, the crosssection of the beam was divided into 60 equal layers. The second portion refers to the equivalent bending stiffness for the steel $E l_{\text {eqa }}$ and it is determined by the following expression:

$$
\mathrm{EI}_{\mathrm{eqa}}=\Sigma_{\mathrm{k}=1}^{\mathrm{nb}} \mathrm{E}_{\mathrm{ak}}\left(\frac{\pi \emptyset_{\mathrm{k}}^{4}}{64}+\frac{\pi \emptyset_{\mathrm{k}}^{2}}{4} \mathrm{y}_{\mathrm{ai}}{ }^{2}\right)
$$

Where $n_{b}$ is the number of bars; $\phi_{k}$ is the bar diameter $k$; $E_{a k}$ is the longitudinal modulus of elasticity of the bar steel $k$; and $y_{a i}, i=1,2$, is the distance from the bar centroid $k$ to the geometric center of the cross-section of the beam. Thus, the total equivalent bending stiffness $E l_{e q}$ is calculated, in a simplified way, by the sum of the portions $E l_{\text {eqc }}$ and $E l_{\text {eqa }}$ :

$$
\mathrm{EI}_{\mathrm{eq}}=\mathrm{EI}_{\mathrm{eqc}}+\mathrm{EI}_{\mathrm{eqa}}
$$

When obtaining the vector of the internal elemental force, the equivalent bending stiffness is determined for each Gauss point in the numerical integration using the Gaussian Quadrature method. In the process for calculating the equivalent stiffness, in order to simplify it, we suppose that the neutral line $\left(\sigma_{x}=0\right)$ is located in the centroid of the cross-section; this condition is valid if there is a symmetry of the armature (lower and upper longitudinal armatures with the same area and symmetrically positioned in relation to the centroid) and if the materials have a linear elastic behavior (Hooke's law). However, when the materials (concrete and/or steel) present a non-linear behavior, the location of the neutral line is altered. Thus, in a non-linear analysis, the positioning of the neutral line is altered for each numerical iteration.

The results obtained from the computational simulations with the proposed modeling varying the $\varepsilon_{d 0}$ parameter are shown in Figure 2 , as well as the experimental and numerical curves (obtained with the Ansys software) presented in the work of Jarek et al. [7]. This example shows an important aspect of the Mazars' model in relation to the sensitivity of the results with regards to the variation of the parameter $\varepsilon_{d 0}$. The damage determined at the Gauss points appear in the material when the equivalent strain reaches the ref-
Figure 2 - Maximum displacement curve versus load increment

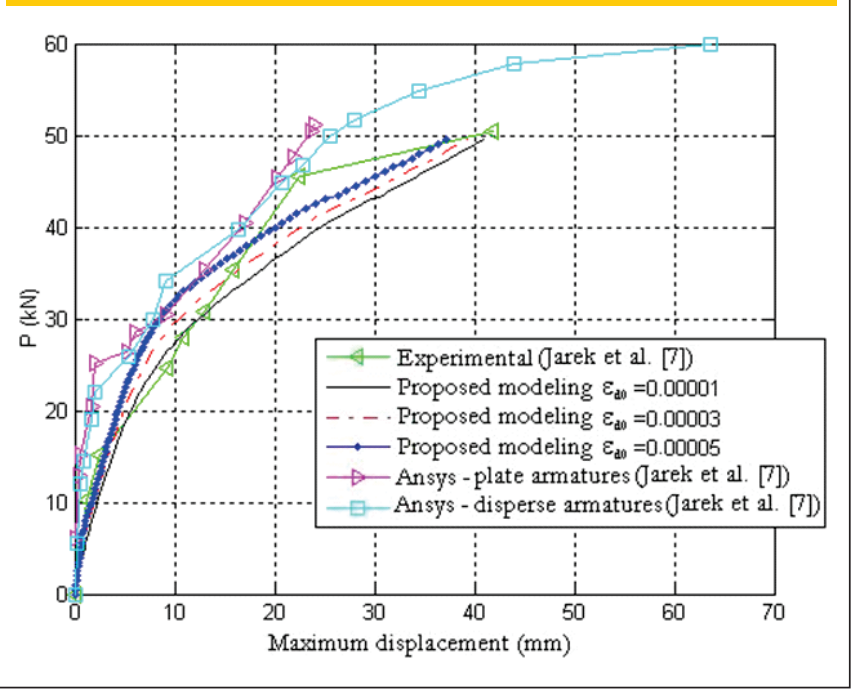

erence strain $\varepsilon_{d 0}$, occasioning thus, the stiffness decrease in the corresponding point.

In accordance with Figure 2, it can be seen that the predicted numerical responses with the proposed modeling for the beam are more stiff (smaller displacements) for $\varepsilon_{d 0}$ equal to 0.00003 and 0.00005 up to a given load increment, if compared to the experimental ones. Differently, for $\varepsilon_{\mathrm{d} 0}$ equal to 0.00001 , the maximum displacement $v$ takes on higher numerical values from the beginning of the analysis. It can also be noticed that there is a linear behavior trend in the load-displacement relation from a certain load value and it maintains itself up to the rupture point. According to the authors Guello and Bittencourt [5], simulations with the Mazars' model can lead to excessive strains in the structure from a given loading. In order to limit these strains, these authors suggest limiting the damage value during the analysis, i.e., have $D_{T}<1$ and $D_{C}$ $<1$. However, such restrictions were not considered in the simulations carried out with the proposed modeling.

Considering the uniaxial stress case $\left(\sigma_{1 \neq} 0, \sigma_{4 \neq} 0\right.$ and $\left.\sigma_{2}=0\right)$, Equation (23) is re-written the following way:

$$
\mathrm{F}_{1} \sigma_{1}+\mathrm{F}_{11} \sigma_{1}{ }^{2}+\mathrm{F}_{44} \sigma_{4}{ }^{2}=1
$$

For all the simulations achieved by varying $\varepsilon_{d 0}$, the beam collapses when $P$ reaches a value of approximately $50 \mathrm{kN}$, getting close to the experimental rupture load. In the computational model, it is considered that the part fails when one of the finite elements of the mesh, in one of the Gauss points, fails, i.e., when the inequality $F_{1} \sigma_{1}+F_{11} \sigma_{1}^{2}+F_{44} \sigma_{4}^{2}>1$ is satisfied (result evaluated from the determination of the maximum stresses in the corresponding crosssection: $\sigma_{1}=\sigma_{x}$ and $\sigma_{4}=\sigma_{x} / 2$ ).

Differences in the answers obtained from the three-dimensional models (with plate and disperse armatures) with the help of the Ansys software (Jarek et al. [7]) and the implemented in this work. These dif- 


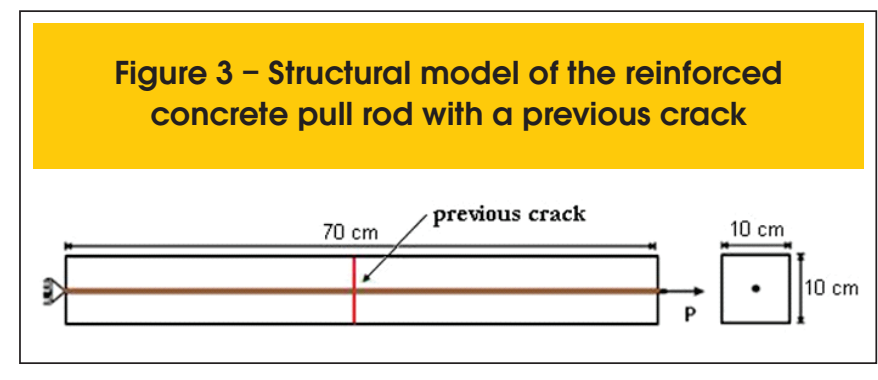

ferences can be explained through some factors such as: the model implemented in this work is unidimensional and it adopts the constitutive relation for the concrete based on the Continuous Damage Mechanics; in the work of Jarek et al. [7], in order to simulate the concrete cracking by evaluating its behavior in relation to the tensile stress, the Willan-Warnke criterion was used; and for its behavior in relation to the compression, the von Mises plastification criterion was used.

\subsection{Simulation 2}

The two-dimensional problem was adapted from Mazars and Pijaudier-Cabot [11]. The problem consists of a reinforced pull rod with $70 \mathrm{~cm}$ in length and rectangular cross-section $(10 \times 10) \mathrm{cm}^{2}$, with a steel bar with moment of inertia $I=490.87 \mathrm{~mm}^{4}$ located in the centroid of the section (Figure 3 ). A tensile force $P=23823.53$ $\mathrm{kN}$ is applied to the free end of the pull rod. It was admitted that the steel has a non-elastic behavior, which is the same as to suppose that $k_{s}$ is equal to 1 , the value used for $\varepsilon_{s y}$ being irrelevant.

For the problem discretization, 310 isoparametric linear plane elements were considered: 270 to simulate the concrete and 31 to simulate the steel bar. Nine line interface elements were used to simulate the discontinuity. The modified Newton-Raphson method combined with the arc-length technique was used in the simulations carried out with this model. The maximum admitted errors at the end of each load increment were $u_{t o l}=10^{-3}$ and $Q_{t o l}=10^{-3}$. The symmetric geometry of the pull rod permitted the modeling of half of the pull rod. The material parameters are given in Table 2 .

The maximum displacement curves versus load obtained from the proposed modeling by varying the value of $\varepsilon_{d 0}$, from Mazars and PijaudierCabot [11] and from Guello [4] are presented in Figure 4. As for the obtained results, it was verified that the curves obtained from the simulations with the proposed modeling were close to the curve obtained from the numerical model of Mazars and Pijaudier-Cabot [11].

\begin{tabular}{|ccc|}
\hline \multicolumn{3}{|c|}{$\begin{array}{c}\text { Table 2 - Material parameters } \\
\text { of the structural model }\end{array}$} \\
\hline Concrete & Steel & Interface \\
\hline$E_{c 0}=30 \mathrm{GPa}$ & $\mathrm{E}_{\mathrm{a}}=200 \mathrm{GPa}$ & $\mathrm{G}_{\mathrm{f}}=4.8710^{-4} \mathrm{kN} / \mathrm{cm}$ \\
$v=0.2$ & $v=0.2$ & $\mathrm{~K}_{0}=0.158 \mathrm{kN} / \mathrm{cm}^{2}$ \\
$\mathrm{~A}_{\mathrm{T}}=0.8$ & $\mathrm{k}_{\mathrm{a}}=1$ & $\mathrm{~W}_{\mathrm{c}}=0.00616 \mathrm{~cm}^{3}$ \\
$\mathrm{~B}_{\mathrm{T}}=510^{3}$ & - & $\mathrm{S}_{\mathrm{u}}=0.158 \mathrm{kN} / \mathrm{cm}^{2}$ \\
$\mathrm{~A}_{\mathrm{c}}=1.4$ & - & - \\
$\mathrm{B}_{\mathrm{C}}=210^{3}$ & - & - \\
\hline
\end{tabular}

\section{Figure 4 - Maximum displacement curve versus load}

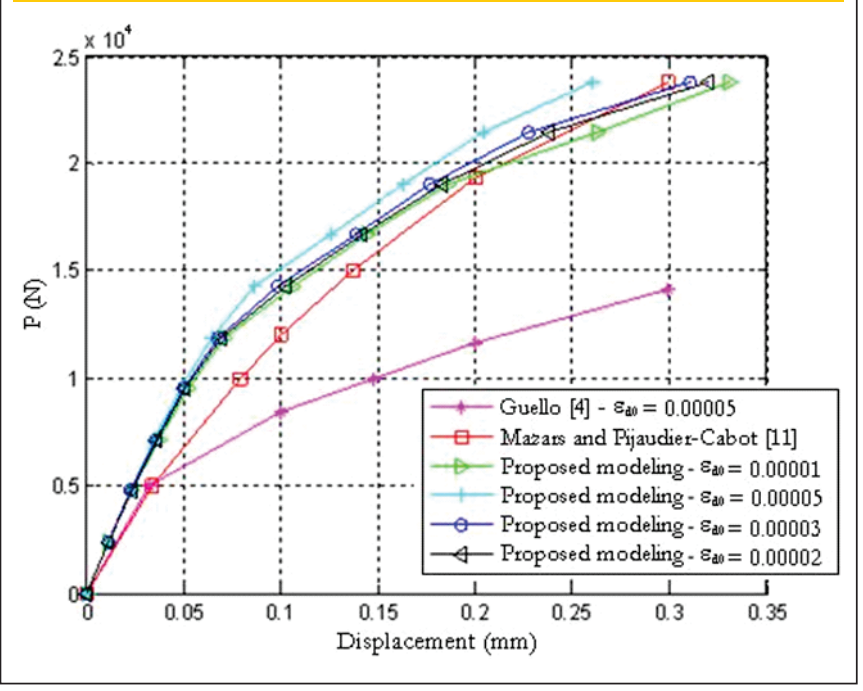

The crack is simulated through the line interface elements with linear softening constitutive behavior. The interface parameters were adopted as per Bessa et al. [2]. Figure 5 shows the maps of the damage distribution in the concrete that correspond to the values of $\varepsilon_{d 0}$ equal to $0.00001,0.00003$ and 0.00005 . In all the cases, it is noticed the formation of new cracks in the transversal direction to the pull rod and parallel to the existing one, as well as cracks around the bar. The pulling off the steel bar did not happen. The variation of the $\varepsilon_{d 0}$ value causes differences in the distribution of the damage in the part once the Mazars' model predicts the appearance of damage in different spots of the pull rod for each value.

The cracks that are perpendicular to the part axis will develop if the tensile stress in the concrete exceeds the tensile stress resistance, not only around the steel bar but also in the entire cross-section. These cracks are basically due to the tensile stress from the stress transference from the steel to the concrete through the adherence. In fact, in reinforced concrete parts under tensile stress, a relative sliding always occurs between the armature and the adjacent concrete when the strains in both of them have different values. This sliding occurs mainly due to the crushing of the concrete in front of the armature bar saliences (Bessa et al. [2]).

Moreover, the contribution of the tangential stiffness component $\left(K_{s}\right)$ is disregarded in the constitutive model for simulating the crack. This simplification may result in singularity and instability in the numerical analysis once the tangential relative displacement is without restriction.

\section{Conclusions}

The traditional analysis of concrete structures is based on laboratory tests in structures or structural parts. The results obtained from these tests are limited and, sometimes, difficult to interpret. Thus, the development of mathematical-numerical models is needed to complement the experimental analysis and allow the generalization of results for different structures and types of loading. 
In relation to the first simulation, the computational numerical model implemented in this work, even it being one-dimensional, was able to reasonably reproduce the results with regards to the other answers obtained in Jarek et al. [7]. The rupture load predicted by the criterion of Tsai and $\mathrm{Wu}$ [18] was close to the experimental collapse load. However, depending on the adopted value for the reference strain $\varepsilon_{d 0}$, the numerical answer may differ and lead to non-satisfactory results.

Tsai and Wu's [18] theory was chosen for presenting many advantages in relation to the several other existing theories, such as: it is a scalar and invariant equation in which the strength components are expressed in a tensor; and the symmetry properties of the tensor may be strictly determined.

The second problem is a study of the coupling of theories - Damage Mechanics and Fracture Mechanics - for simulating the phenomena related to the concrete behavior.

The structural analysis of reinforced concrete parts with a previous crack (discontinuity) carried out through the line interface element, for simulating the crack - together with a model of damage, has proved to be satisfactory from the qualitative point of view, for the maps of the damage distribution once all the simulations presented perpendicular cracks to the pull rod axis and parallel among themselves.

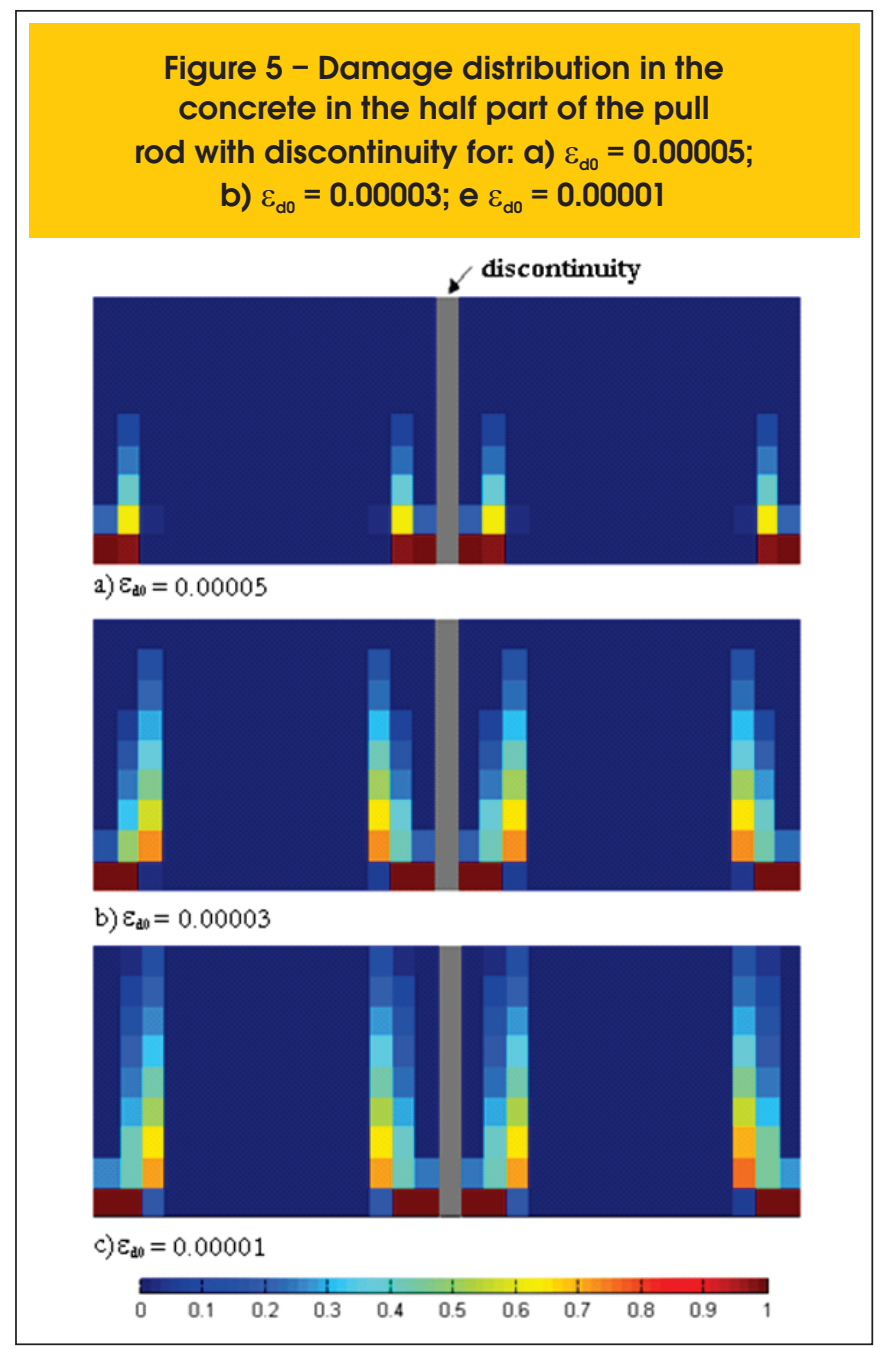

This methodology has the advantage of not requiring the use of finite element mesh reconstruction techniques. In general, discreet models require sophisticated and expensive mesh reconstruction techniques, from the computational point of view, for capturing the propagation of cracks along the loading process.

It is believed that the adoption of constitutive models that consider the coupling of theories present a great potential for projects used for calculating the collapse load and identifying all the mechanism, for verifying the behavior of finite elements under stress and in the analysis of reinforced concrete structures subject to random loads, for instance, the ones from the shocks, and also for verifying the deformability of the structures in use.

The joint application of such models in practical situations is harmed due to the experimental identification of the parameters contained in the evolution laws of the damage and fracture variables. According to Pituba and Proença [13], the Mazars' [10] model can be expanded for use in situations that are more close to reality, provided that resources such as the armatures plastification, location of permanent strains and the consideration of the interaction between the concrete and the armature are incorporated. In future works, besides the suggestions from these authors, we intend to implement new constitutive models based on the Continuous Damage Mechanics for simulating the concrete and other failure criteria, such as the Willian-Warnke, in two-dimensional and three-dimensional reinforced concrete structures, which will allow more realistic analyses.

\section{Bibliography}

[01] ÁlVARES, M. S.; PROENÇA, S. P. B.; BILLARDON, $R$. Estudo e emprego de um modelo de dano localizado: aplicação a vigas em concreto armado. In: XX CILAMCE - Congresso Ibero-Latino Americano Sobre Métodos Computacionais para Engenharia, São Paulo, 1999.

[02] BESSA, V. M. R. d'A.; QUININO, U. C. M.; BITTENCOURT, E.; ITURRIOZ, I. Análise da fissuração de um tirante de concreto simples comparação de diferentes metodologias. In: $\mathrm{V}$ Simpósio EPUSP sobre Estruturas de Concreto, São Paulo, 2003.

[03] GAGLIARDO, D. P.; GAGLIARDO, J. C.; MASCIA N. T. Comparação entre os critérios de Rankine e de Tsai Wu para uma viga de concreto reforçado com fibras. In: Anais do $53^{\circ}$ Congresso Brasileiro do Concreto - CBC 2011, Florianópolis, SC, 2011.

[04] GUELLO, G. A. Simulação computacional de estruturas de concreto por meio da mecânica do dano. Dissertação (Mestrado), Escola Politécnica da Universidade de São Paulo, São Paulo, 2002.

[05] GUELLO, G. A.; BITTENCOURT, T. N. Simulação Computacional de Estruturas de Concreto por meio da Mecânica do Dano. Boletim Técnico da Escola Politécnica da USP, São Paulo, v. 202, n. 1, p. 1-12, 2002.

[06] HILL, R. A Theory of the Yielding and Plastic Flow of Anisotropic Metals. In: Proceedings of the Royal Society of London, Series A, London, v. 193, p. 281-297, 1948 . 
[07] JAREK, A.; MARCONCIN, L. DO R.; SOUZA, L. A. F.; MACHADO, R. D.; LACERDA, L. A. Numerical modeling combined with experimental analysis of simply supported reinforced concrete beam monitored with fiber optic sensors. In: XXXII Iberian Latin American Congress on Computational Methods in Engineering, Ouro Preto, MG, 2011.

[08] LEMAITRE, J.; CHABOCHE, J. C. Mécanique des matériaux solids. Paris, Dunod-Bordas, 1985.

[09] LEONEL, E. D.; RIBEIRO, G. O.; PAULA, F. A. Simulação Numérica de Estruturas de Concreto Armado por Meio do MEF/ANSYS. In: V Simpósio EPUSP sobre Estruturas de Concreto, São Paulo, 2003.

[10] MAZARS, J. Application de la mécanique de l'endommagement au comportement non lineaire et à la rupture du béton de structure. Thése de Doctorat d'État, Université Paris 6, 1984.

[11] MAZARS, J.; PIJAUDIER-CABOT, G. Continuum damage theory: application to concrete. Journal of Engineering Mechanics, v. 115, n. 2, p. 345-365, 1989.

[12] NICOLAS, E. A.; MASCIA, N. T.; TODESCHINI, $R$. Ensaios uniaxiais e biaxiais para avaliação de critério de resistência (Tsai-Wu) de materiais anisotrópicos para a madeira. Minerva 6 (2), p. 107-116, 2006.

[13] PITUBA, J. J. C.; PROENÇA, S. P. B. Estudo e aplicação de modelos constitutivos para o concreto fundamentados na mecânica do dano contínuo. Cadernos de Engenharia de Estruturas, v. 7, n. 23, p. 33-60, 2005.

[14] PROENÇA, S. P. B. Simulação numérica do comportamento de elementos estruturais em concreto e argamassa armada pelo emprego de um modelo de dano. Revista Internacional de Métodos Numéricos para Cálculo y Diseño en Ingeniería, v. 8, 4, 351-360, 1992.

[15] RAMM, E. Strategies for tracing the nonlinear response near limit points. Euro-US-Worshop on Nonlinear Finite Element Analysis in Structural Mechanics, Ruhr Universitat Bochum, pp. 68-89, Springer, Berlin, 1981.

[16] SCHELLEKENS, J. C. J. Interface Elements in Finite Elements Analysis. TNO-BI-90-165, 1990.

[17] TIAGO, C. M.; LEITÃO, V. M. A.; ROSCA, V. Análise de problemas unidimensionais de mecânica do dano com funções de base radial. J.M. Goicolea, C. Mota Soares, M. Pastor e G. Bugeda, Editor, Métodos Numéricos en Ingeniería V, Artes Gráficas Torres S.A., 2002.

[18] TSAI, S. W.; WU, E. M. A general theory of strength for anisotropic materials. Journal of Composite Materials, n. 1, v. 5, p. 58-80. Jan., 1971. 